\title{
Efeito de indutores de resistência em cafeeiro contra a mancha de Phoma
}

\author{
Gutemberg Barone Araújo Nojosa*, Mário Lúcio Vilela Resende, Beatriz Meireles Barguil*, Sylvia Raquel Gomes \\ Moraes \& Carla Heloísa Vilas Boas
}

Universidade Federal de Lavras, Depto Fitopatologia, Cx. Postal 37, Lavras-MG, Brasil, CEP 37200-000, *Bolsista CAPES

Autor para correspondência: Gutemberg Barone Araújo Nojosa gutemberg.barone@agricultura.gov.br

Data de chegada: 06/08/2007. Aceito para publicação em: 13/11/2008

\section{RESUMO}

Nojosa, G.B.A.; Resende, M.L.V., Barguil, B.M.; Moraes, S.R.G. \& Vilas Boas, C.H. Efeito de indutores de resistência em cafeeiro contra a mancha de Phoma. Summa Phytopathologica, v.35, n.1, p.60-62, 2009

O efeito dos produtos acibenzolar S-metil ester (ASM, Bion ${ }^{\circledR}$ ), fosfito de potássio (Hortifós PK®) e de um fertilizante foliar (Nutex Axcell $\left.{ }^{\circledR}\right)$ foi avaliado sobre a germinação de esporos e no crescimento micelial de Phoma costarricensis. O efeito desses produtos também foi avaliado na severidade da mancha de Phoma em mudas de cafeeiro. O percentual de germinação dos conídios de $P$. costarricensis não foi afetado pelas doses de fosfito e ASM, mas reduções no crescimento micelial do fungo foram observadas. A AACPD e a severidade da doença foram menores em todos os tratamentos quando comparados com a testemunha inoculada. Nas plantas tratadas com o fungicida tebuconazole, utilizado como padrão, foi observada redução de 50,9\% na severidade da doença. Os menores valores de severidade e de AACPD foram observados nas plantas tratadas com ASM 0,1 g/L; Fosfito 2,5 $\mathrm{mL} / \mathrm{L}$; Fosfito 5,0 mL/L e o fertilizante Nutex Axcell ${ }^{\circledR}$ 4,0 mL/L.

Palavras-chave adicionais: Coffea arabica, elicitores, Phoma costarricensis.

\section{ABSTRACT}

Nojosa, G.B.A.; Resende, M.L.V., Barguil, B.M.; Moraes, S.R.G. \& Vilas Boas, C.H. Effect of resistance inducers on coffee against Phoma leaf spot. Summa Phytopathologica, v.35, n.1, p.60-62, 2009

The effect of acibenzolar S-metil ester (ASM, Bion ${ }^{\circledR}$ ), potassium phosfite (Hortifós PK ${ }^{\circledR}$ ) and of a foliar fertilizer (Nutex Axcell ${ }^{\circledR}$ ) was assessed on the spore germination and mycelial growth of Phoma costarricensis. The effect of these products on severity of Phoma leaf spot was also assessed on coffee seedlings. The percentage of conidial germination of $P$. costarricensis was not affected by doses of phosfite and ASM, but reductions on the mycelial growth of the fungus were detected. The area under the disease progress curve (AUDPC) and the disease severity were lower in all treatments compared to the inoculated control. There was a reduction of $50.9 \%$ on disease severity in plants treated with the standard fungicide tebuconazole. Low values for severity and AUDPC were observed when plants were treated with ASM $0.1 \mathrm{~g} / \mathrm{L}$; phosfite $2.5 \mathrm{~mL} / \mathrm{L}$; phosfite $5.0 \mathrm{~mL} / \mathrm{L}$ and the fertilizer Nutex Axcell ${ }^{\circledR}$ at $4.0 \mathrm{~mL} / \mathrm{L}$, which differed from other treatments.

Keywords: Coffea arabica, elicitors, Phoma costarricensis.

O patógeno Phoma costarricensis Echandi infecta várias partes da planta de cafeeiro (5), causando a doença conhecida como mancha de Phoma, que pode ter um potencial de dano elevado sob condições ambientais propícias. Almeida \& Matiello (2) quantificaram perdas de $15 \%$ a 43\% da produção no Sul de Minas Gerais, em regiões favoráveis à doença com temperatura em torno de $20^{\circ} \mathrm{C}$ e umidade relativa superior a $80 \%$.

Alguns trabalhos já foram conduzidos visando verificar o efeito de fungicidas de diferentes princípios ativos e publicados em anais de congressos realizados no Brasil, contando com aproximadamente 17 produtos registrados para o controle da mancha de Phoma em cafeeiro, sendo 13 princípios ativos distribuídos em 11 grupos químicos (1). Entretanto, diante do novo paradigma ecológico da agricultura sustentável é necessário buscar alternativas para os fungicidas no controle de patógenos, com menor custo para o ambiente e segurança para o consumidor. Barguil et al. (3) verificaram redução de 35\% na severidade da mancha de Phoma em mudas de cafeeiro pulverizadas com extratos de folha de cafeeiro ou produtos a base de biomassa cítrica (Ecolife ${ }^{\circledR}$ e Agromil $\left.{ }^{\circledR}\right)$. Da mesma maneira, produtos disponíveis no mercado como indutores de resistência e fertilizantes podem propiciar a redução da severidade neste e em outros patossistemas (10).

Portanto, objetivou-se estudar o efeito dos produtos acibenzolar S-metil ester (ASM, Bion ${ }^{\circledR}$, Syngenta Proteção de Cultivos Ltda), fosfito de potássio (Hortifós PK®, Agrichem do Brasil Ltda) e de um fertilizante foliar a base de boro, cobre, enxofre, manganês e zinco (Growmaster Axcell ${ }^{\circledR}$, Intercuf Ind. \& Com. Ltda) na germinação dos conídios e no crescimento micelial de $P$. costarricensis e na severidade da mancha de Phoma em cafeeiro.

Foi utilizado um isolado de $P$. costarricensis obtido de cafeeiros na região de Lavras - MG. Para obter o inóculo, as folhas infectadas foram lavadas em água corrente, desinfestadas com hipoclorito de sódio 2\% e deixadas em câmara úmida por 24 horas para esporulação. Os conídios foram transferidos para placas de Petri contendo meio batata-dextrose-ágar (BDA). A cultura pura foi mantida a $23^{\circ} \mathrm{C}( \pm 2)$ por 12 dias, sendo preservada em tubo de ensaio.

A inibição da germinação dos conídios de $P$. costarricensis foi avaliada em placas de Petri contendo o meio ágar-água. Foram adicionados sobre o meio $100 \mu \mathrm{L}$ de conídios de $P$. costarricensis na concentração de 2 x $10^{4}$ conídios/mL de água destilada estéril (ADE) e 
Tabela 1. Efeito dos produtos na germinação de conídios e no crescimento micelial de Phoma costarricensis.

\begin{tabular}{lcccc}
\hline Tratamentos & Concentração do produto & Germinação de conídios (\%)* & Crescimento micelial (cm)* & Inibição do crescimento (\%) \\
\hline Testemunha & - & $82 \mathrm{a}$ & $7,87 \mathrm{a}$ & 0,0 \\
\hline Tebuconazole & $0,12 \mathrm{~mL} / \mathrm{L}$ & $0 \mathrm{~b}$ & $0,00 \mathrm{f}$ & 100,00 \\
& $0,25 \mathrm{~mL} / \mathrm{L}$ & $0 \mathrm{~b}$ & $0,00 \mathrm{f}$ & 100,00 \\
& $0,50 \mathrm{~mL} / \mathrm{L}$ & $0 \mathrm{~b}$ & $0,00 \mathrm{f}$ & 100,00 \\
& $1,00 \mathrm{~mL} / \mathrm{L}$ & $0 \mathrm{~b}$ & $0,00 \mathrm{f}$ & $9,00,00$ \\
\hline ASM & $0,02 \mathrm{~g} / \mathrm{L}$ & $85 \mathrm{a}$ & $7,13 \mathrm{a}$ & 17,34 \\
& $0,05 \mathrm{~g} / \mathrm{L}$ & $67 \mathrm{a}$ & $6,51 \mathrm{~b}$ & 38,06 \\
& $0,10 \mathrm{~g} / \mathrm{L}$ & - & $4,88 \mathrm{c}$ & 56,23 \\
\hline Fosfito de potássio & $0,20 \mathrm{~g} / \mathrm{L}$ & - & $3,45 \mathrm{~d}$ & 0,38 \\
& $1,25 \mathrm{~mL} / \mathrm{L}$ & $7,84 \mathrm{a}$ & 11,31 \\
& $2,50 \mathrm{~mL} / \mathrm{L}$ & $63 \mathrm{a}$ & $6,98 \mathrm{a}$ & 13,98 \\
& $5,00 \mathrm{~mL} / \mathrm{L}$ & $69 \mathrm{a}$ & $6,77 \mathrm{~b}$ & 62,26 \\
\hline Fertilizantefoliar & $10,00 \mathrm{~mL} / \mathrm{L}$ & $71 \mathrm{a}$ & $2,97 \mathrm{e}$ & 0,00 \\
& $0,50 \mathrm{~mL} / \mathrm{L}$ & $79 \mathrm{a}$ & $7,97 \mathrm{a}$ & 5,84 \\
\hline CV (\%) & $1,00 \mathrm{~mL} / \mathrm{L}$ & - & $7,41 \mathrm{a}$ & 6,54 \\
\hline
\end{tabular}

*Médias seguidas pela mesma letra na coluna não diferem entre si pelo teste de Scott \& Knott a 5\%.

- Dosagens não avaliadas com relação a germinação de conídios.

igual volume de cada produto a ser testado. As placas de Petri foram incubadas em câmara úmida a $21^{\circ} \mathrm{C}$ por 24 horas, sendo então analisadas ao microscópio ótico para a contagem do número de conídios germinados. O ensaio foi conduzido em delineamento inteiramente casualizado (DIC) com três placas por tratamento, sendo amostrados 200 conídios/placa.

Para avaliar o crescimento micelial, os indutores utilizados foram adicionados ao meio BDA e distribuídos em placas de Petri, sendo depositado em cada placa um disco de 0,6 cm de diâmetro contendo parte do micélio de $P$. costarricensis. O ensaio foi estabelecido em DIC com 10 repetições por tratamento. Na testemunha, o patógeno foi inoculado apenas em meio BDA. As placas de Petri foram mantidas em câmara de crescimento, a temperatura de $22^{\circ} \mathrm{C}( \pm 2)$ e fotoperíodo de $12 \mathrm{~h}$. As avaliações foram finalizadas após 14 dias, quando o micélio do tratamento testemunha preencheu a placa de Petri. A percentagem de inibição do crescimento foi calculada para cada dosagem em relação à testemunha. Os seguintes tratamentos foram avaliados nos ensaios de germinação e crescimento: 1) Testemunha: ADE; 2) Tebuconazole nas concentrações de 0,12; 0,25; 0,50 e 1,00 mL/L; 3) Acibenzolar S-metil ester (ASM) nas concentrações de 0,025; 0,05; 0,10 e 0,20 g/L; 4) Fosfito de potássio nas concentrações de 1,$25 ; 2,5 ; 5,00$ e $10,00 \mathrm{~mL} / \mathrm{L} ; 5$ ) Fertilizante foliar nas concentrações de 0,5; 1,0; 2,0 e 4,0 mL/L.

No experimento in vivo foi utilizado delineamento em blocos casualizados, com dez tratamentos e quatro repetições, sendo cada repetição composta por dez mudas da cultivar Acaiá Cerrado com 10 meses de idade, mantidas em casa de vegetação $\left(26^{\circ} \mathrm{C} \pm 3\right)$. As plantas foram pulverizadas com os seguintes tratamentos: 1) Testemunha pulverizada com ADE; 2) Tebuconazole 2,5 mL/L; 3) ASM 0,1 g/L; 4) ASM 0,2 g/L; 5) ASM 0,4 g/L; 6) Fosfito de potássio 1,25 mL/L; 7) Fosfito de potássio $2,5 \mathrm{~mL} / \mathrm{L}$; 8) Fosfito de potássio $5,0 \mathrm{~mL} / \mathrm{L}$; 9) Fertilizante foliar 2,0 mL/L; 10) Fertilizante foliar 4,0 mL/L. Após sete dias, as mudas foram inoculadas com uma suspensão de $2 \mathrm{x}$ $10^{4}$ conídios/mL com pulverizador manual. A severidade da doença foi avaliada por dois avaliadores observando-se o percentual de área lesionada aos três, seis, nove e 12 dias após a inoculação, utilizando a escala de Horsfall \& Barrat (8).

Após obter os dados de severidade foram calculadas as áreas abaixo da curva de progresso da doença (AACPD). Os valores dos percentuais de germinação e de crescimento, da severidade aos 12 dias e da AACPD foram submetidos à análise de variância e as médias comparadas pelo teste de Scott \& Knott a 5\% com o programa estatístico SAEG (Universidade Federal de Viçosa).

O fungicida tebuconazole inibiu em $100 \%$ a germinação dos conídios em todas as dosagens avaliadas. As doses de ASM e fosfito de potássio testadas não diferiram do tratamento testemunha em relação à inibição da germinação dos conídios de $P$. costarricensis (Tabela 1).

O ASM e o fosfito de potássio inibiram em 56,23 e 62,26\%, respectivamente, o crescimento micelial de $P$. costarricensis na maior dose testada, enquanto que o fertilizante foliar pouco interferiu no crescimento (Tabela 1). O fungicida tebuconazole inibiu totalmente o crescimento micelial em todas as doses testadas. Kataria et al. (9) observaram que o ASM na dose de $2 \mathrm{mM}$ reduziu em $50 \%$ o crescimento micelial de Rhizoctonia solani, enquanto que o ácido salicílico e o ácido clorosalicílico inibiram $100 \%$ do crescimento micelial na dose de 10mM. Grant et al. (7) também observaram redução do crescimento micelial de isolados de Phytophthora infestans com dosagem a partir de $1 \mathrm{mM}$ de fosfito. Embora o fosfito e o ASM não tenham apresentado efeitos significativos sobre a germinação, característica desejada mas não absoluta para um indutor de resistência, esses indutores interferiram no crescimento micelial de $P$. costarricensis. Essa inibição pode ser devido às condições desfavoráveis ao fungo no ensaio in vitro pelo fato deste estar em contato direto com os indutores, o que talvez não se repetisse em casa de vegetação ou em campo.

Os tratamentos diferiram significativamente entre si e a maior severidade da doença foi observada no tratamento onde as plantas foram pulverizadas apenas com água (Figura 1A). O tratamento com ASM na dosagem de 0,4 g/L apresentou menor eficiência de controle da doença, quando comparado as outras dosagens e produtos. Nas 

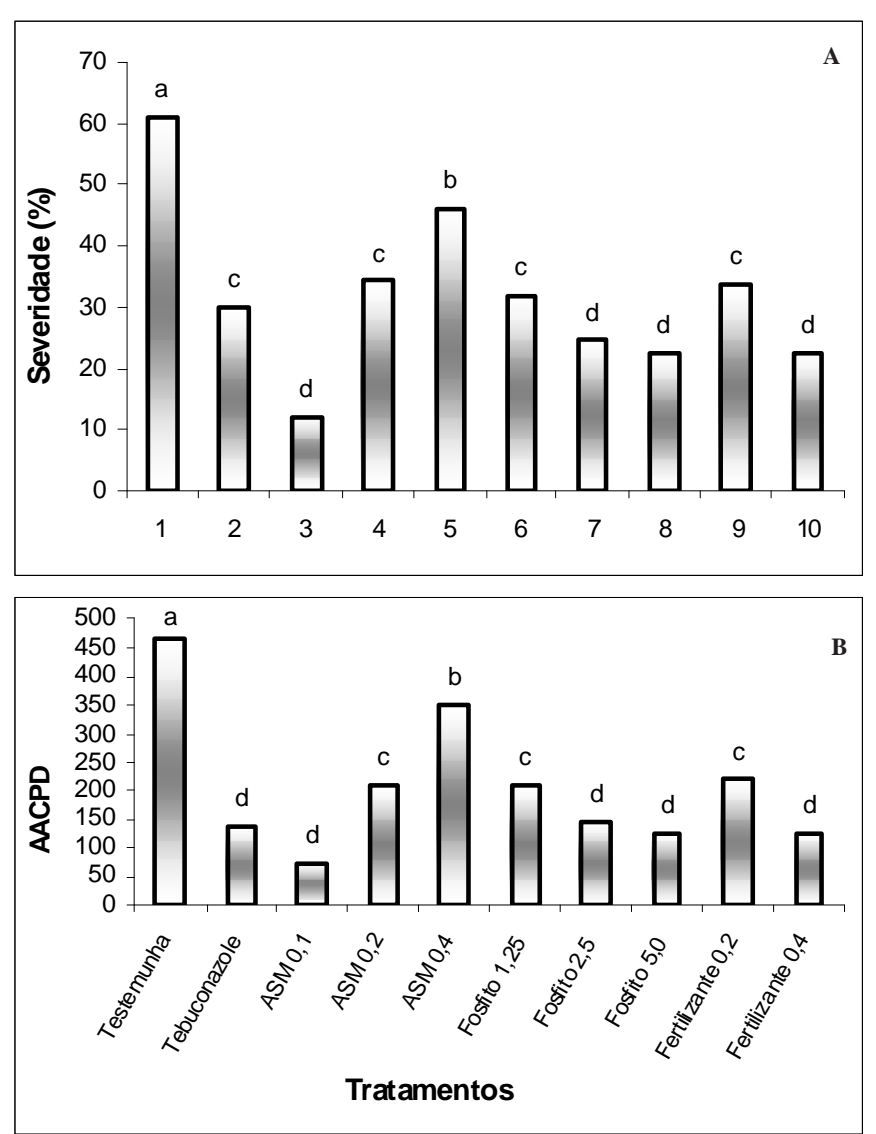

Figura 1 - Severidade aos doze dias após a inoculação (A) e área abaixo da curva de progresso da doença - AACPD (B) em mudas de cafeeiro pulverizadas com produtos sete dias antes da inoculação com Phoma costarricensis. Tratamentos com a mesma letra não diferem entre si pelo teste de Scott \& Knott a 5\% de probabilidade. O coeficiente de variação em (A) e (B) foi de 20,59 e $24,93 \%$, respectivamente.

plantas tratadas com o fungicida tebuconazole foi observada redução de 50,9\% na severidade da doença e de 70,7\% na AACPD quando comparado à testemunha (Figura $1 \mathrm{~A} \mathrm{e} \mathrm{1B).} \mathrm{Para} \mathrm{os} \mathrm{possíveis} \mathrm{indutores}$ de resistência, os menores valores de severidade e AACPD foram observados nas plantas tratadas com ASM 0,1 g/L; Fosfito 2,5 mL/L; Fosfito 5,0 mL/L e o fertilizante 4,0 mL/L, que reduziram a severidade da doença em 80,00; 60,06; 63,18 e 63,40\%, respectivamente, sendo esses percentuais superiores ao observado em plantas tratadas com tebuconazole (Figura 1Ae 1B). Venâncio et al. (11) relataram a eficiência de ASM no controle de Cercospora coffeicola em mudas de cafeeiro, onde o menor número de lesões foi observado em plantas tratadas com $50 \mathrm{ppm}$ do produto. O fosfito de potássio na dosagem de $7 \mathrm{~mL} / \mathrm{L}$ foi eficiente no controle de míldio em mudas de couve-flor de sete e de 30 dias de idade, apresentando efeito protetor por 15 dias (4). É importante ressaltar que o ASM proporcionou maior AACPD nas maiores dosagens, enquanto que o fosfito de potássio e o fertilizante foliar apresentaram maior AACPD nas menores dosagens. No patossistema tomate - Alternaria solani, a aplicação foliar de ASM propiciou aumento na severidade da doença e também interferiu diretamente no crescimento micelial do patógeno (6). Diante dos resultados obtidos considera-se importante o teste desses produtos para o controle da mancha de Phoma do cafeeiro no campo.

\section{REFERÊNCIAS BIBLIOGRÁFICAS}

1. AGROFIT. Sistema de agrotóxicos Fitossanitários. Disponível em: <http://extranet. agricultura.gov.br/agrofit_cons/ principal_agrofit_cons>. Acesso em: 20 abr. 2007.

2. Almeida, S.R.; Matiello, J.B. Estudo de novos produtos para controle químico a Phoma spp. em cafeeiros, a nível de campo. In: Congresso Brasileiro de Pesquisas Cafeeiras, 15. 1989, Maringá, Anais. 1989. p.145-146.

3. Barguil, B.M.; Resende, M.L.V.; Resende, R.S.; Beserra Júnior, J.E.A.; Salgado, S.M.L. Effect of extracts from citric biomass, rusted coffee leaves and coffee berry husks on Phoma costarricensis of coffee plants. Fitopatologia Brasileira, Brasília, v. 30, n. 5, p. 535-537, 2005.

4. Bécot, S.; Pajot, E.; Le Corre, D.; Monot, C.; Silué, D. Phytogard ${ }^{\circledR}$ (K HPO ) induces localized resistance in cauliflower to downy miłdew ${ }^{3}$ of crucifers. Crop Protection, London, v. 19, p. 417425, 2000.

5. Echandi, E. La quema de los cafetos causada por Phoma costarricensis. Revista de Biología Tropical, San José, v. 5, p. 81-102, 1957.

6. Fritz, M. Resistance induction in the pathosystem tomato Alternaria solani. 2005. 124p. Thesis Doktorgrades der Biometrie und Populationsgenetik - Institut für Pflanzenbau und Pflanzenzüchtung II der Justus, Universität Liebig Gießen.

7. Grant, B.R.; Grant, J.; Harris, J. Inhibition of growth of Phytophthora infestans by phosphate and phosphonate in defined media. Experimental Mycology, Orlando, v. 16, p. 240-244, 1992.

8. Horsfall, J.C. \& Barrat, R.W. An improved grading system for measuring plant diseases. Phytopathology, St. Paul, v. 35, p. $665,1945$.

9. Kataria, H.R.; Wilmsmeier, B.; Buchenauer, H. Efficacy of resistance inducers, free-radical scavengers and an antagonist strain of Pseudomonas fluorescens for control of Rhizoctonia solani AG-4 in bean and cucumber. Plant Pathology, London, v. 46, p. 897-909, 1997.

10. Nojosa, G.B.A.; Resende, M.L.V.; Resende, A.V. Uso de fosfitos e silicatos na indução de resistência. In: Cavalcanti, L.S.; Di Piero, R.M.; Cia, P.; Pascholati, S.F.; Resende, M.L.V.; Romeiro, R.S.. (Org.). Indução de resistência em plantas a patógenos e insetos. Piracicaba: FEALQ, 2005. v. 1, cap. 6, p. 139-153.

11. Venâncio, W.S.; Zagonel, J.; Furtado, E.L.; Souza, N.L.; Peres, N.A.R. Novos fungicidas. II - Famoxadone e indutores de resistência. Revisão Anual de Patologia de Plantas, Passo Fundo, v. 8, p. 59-92, 2000. 